\title{
Flow-assisted surgical cerebral revascularization
}

\author{
William W. Ashley, Jr., M.D., Ph.D., Sepideh Amin-Hanjani, M.D., Ali Alaraj, M.D., \\ John H. Shin, M.D., AND FAdY T. ChaRbel, M.D.
}

Department of Neurosurgery, University of Illinois at Chicago

\begin{abstract}
$\checkmark$ Extracranial-intracranial bypass surgery has advanced from a mere technical feat to a procedure requiring careful patient selection and a justifiable decision-making paradigm. Currently available technologies for flow measurement in the perioperative and intraoperative setting allow a more structured and analytical approach to decision making. The purpose of this report is to review the use of flow measurement in cerebral revascularization, presenting algorithms for flow-assisted surgical planning, technique, and surveillance. (DOI: 10.3171/FOC/2008/24/2/E20)
\end{abstract}

\section{KEY WORDS - cerebral ischemia - cerebral revascularization • extracranial-intracranial bypass $\bullet$ flow}

$\mathrm{T}$ HE evolution of direct surgical cerebral revascularization has been punctuated by 4 phases (Table 1). The Prebypass Development Phase (1939-1966) was defined by a recognized need for cerebral revascularization techniques. In 1912, Carrel $^{14}$ was awarded the Nobel Prize for his work on suturing blood vessels. Building on this early work, pioneering efforts on surgical technique by Pool and Potts, ${ }^{44}$ Jacobson and Suarez, ${ }^{31}$ and others, paved the way for the first successful common carotid artery-ICA bypass by Woringer and Kunlin in $1963,{ }^{56}$ and the first STA-MCA bypass by Donaghy and Yaşargil in 1967..$^{21}$ This ushered in the Technical Advancement Phase (1967-1984). During this period rapid development and refinement of basic microsurgical anastomosis techniques set the stage for modern technical bypass. The focus was on the technical ability to perform various bypass procedures with the implicit understanding that patients with carotid occlusion and ischemia would benefit from revascularization. Pioneering work by Spetzler and Chater, ${ }^{47}$ Tew, ${ }^{53}$ Ausman and colleagues, ${ }^{10,11}$ Khodadad, ${ }^{34}$ Sundt et al., ${ }^{50}$ and others set standards for surgical technique. As techniques became more standardized, the number of bypass procedures increased rapidly. Practitioners soon began to question the clinical utility of this technically challenging procedure. In 1977 the EC-IC Bypass Study was initiated to

\footnotetext{
Abbreviations used in this paper: $\mathrm{BOT}=$ balloon occlusion test; $\mathrm{CFI}=$ cut flow index; COT = clip occlusion test; $\mathrm{CT}=$ computed tomography; EC-IC = extracranial-intracranial; FAS = flow-assisted surgical; $\mathrm{ICA}=$ internal carotid artery; $\mathrm{MCA}=$ middle cerebral artery; $\mathrm{MR}=$ magnetic resonance; $\mathrm{NOVA}=$ Non-invasive Optimal Vessel Analysis; SPECT = single-photon emission computed tomography; STA = superficial temporal artery.
}

address this issue. ${ }^{2}$ The Clinical Refinement Phase (19851995) began with the disappointing results of the EC-IC Bypass Study, which suggested that bypass was of no clinical benefit. ${ }^{23,24}$ Although the surgery fell out of wide favor, some practitioners felt that the study misrepresented the benefit of bypass in properly selected patients. ${ }^{8,12,13}$ Indeed, some continued to perform bypasses in patients with giant aneurysms or other skull base lesions, moyamoya disease, or in certain patients with symptomatic cerebral ischemia refractory to medical therapy. Thus, this phase was characterized by efforts to define a clinical population that could benefit from bypass. Work by Yonas et al ${ }^{55,58}$ and others sought to define this population using Xe CT to obtain quantitative measurements of cerebral blood flow. In addition, novel technical advances by Tulleken and colleagues ${ }^{54}$ offered the possibility of a nonocclusive anastomosis.

Most recently, the Hemodynamic Phase (1997-present) has been characterized by attempts to understand flow and select patients with significant symptomatic impairment. This new focus on hemodynamics has provided a basis for renewed interest in bypass surgery. As a result, the number of bypass procedures has increased by over $400 \%$ from the 4-year period from 1992-1996 to 1997-2000. ${ }^{3}$ Over the last decade, there has been a renaissance in the field of cerebral revascularization. The impetus for this rebirth was the understanding that successful bypass required not only technical expertise but the ability to properly select only high-risk patients who would benefit from revascularization. Indeed work by Grubb and colleagues, ${ }^{20}$ Powers et al. ${ }^{27}$ Derdeyn et al., ${ }^{19}$ and others began to deepen our understanding of cerebral ischemia and to highlight the fact that disturbed hemodynamics was the critical issue.

In the current era, practical and noninvasive quantitative 
W. W. Ashley Jr. et al.

TABLE 1

Evolution of cerebrovascular revascularization*

\begin{tabular}{|c|c|}
\hline \multicolumn{2}{|r|}{ Prebypass development (1939-1966) } \\
\hline 1939 & Pool \& Potts: superficial temporal artery-to-distal anterior cerebral artery shunt using a plastic tube \\
\hline 1960 & Jacobson \& Suarez: microanastomosis techniques for 2-mm blood vessels \\
\hline & $\begin{array}{c}\text { Woringer \& Kunlin: CCA-to-intracranial ICA bypass using a saphenous vein graft } \\
\text { Technical Advancement Phase (1967-1984) }\end{array}$ \\
\hline 1967 & Donaghy \& Yaşargil: 1st STA-MCA bypass in humans \\
\hline 1974 & Spetzler \& Chater: OA-MCA bypass \\
\hline 1975 & Tew: CCA-ICA bypass \\
\hline 1970s & Ausman et al.: OA-PICA (1976), STA-SCA (1979) \\
\hline $1980 \mathrm{~s}$ & Sundt et al: SCA-PCA (1981), ECA-PCA (1982) \\
\hline \multicolumn{2}{|r|}{ Clinical Refinement Phase (1985-1995) } \\
\hline 1985 & EC-IC Bypass Study: no benefit from bypass shown \\
\hline 1986 & Ausman \& Diaz, Awad \& Spetzler: report potential sources of bias in EC-IC bypass study \\
\hline 1995 & $\begin{array}{l}\text { Yonas \& Jungreis: use Xe CT to show that compromised CBF reactivity is a predictor of stroke in patients w/ } \\
\text { symptomatic CA occlusive disease. }\end{array}$ \\
\hline & $\begin{array}{l}\text { Tulleken \& Verdaasdonk: initial intracranial experience w/ ELANA. } \\
\text { Hemodynamic Phase (1996-present) }\end{array}$ \\
\hline 1998 & $\begin{array}{l}\text { Grubb et al: results of St. Louis Carotid Occlusion Study show hemodynamic failure defines a subgroup of } \\
\text { patients w/ symptomatic carotid occlusion who are at high risk for subsequent stroke when treated medically }\end{array}$ \\
\hline $1990 \mathrm{~s}$ & $\begin{array}{l}\text { Charbel et al: ultrasonic perivascular flow probe application in neurosurgery (1998) \& 3D vessel localization to } \\
\text { improve nonnvasive flow quantification using phase-contrast MR imaging (2000) }\end{array}$ \\
\hline 2001 & $\begin{array}{l}\text { Carotid Occlusion Surgery Study: opens to reassess utility of EC-IC bypass in select patients using hemody- } \\
\text { namic selection criterion. Results expected in } 2013 \text {. }\end{array}$ \\
\hline 2007 & $\begin{array}{l}\text { Dacey et al: intracranial automated CCA-MCA bypass using Cardica C-Port xA Distal Anastomosis } \\
\text { System }\end{array}$ \\
\hline
\end{tabular}

* Abbreviations: $\mathrm{CA}=$ carotid artery; $\mathrm{CBF}=$ cerebral blood flow; $\mathrm{CCA}=$ common $\mathrm{CA}$; $\mathrm{ECA}=$ external CA; ELANA = excimerlaser assisted nonocclusive anastomosis; $\mathrm{MCA}=$ middle cerebral artery; $\mathrm{OA}=$ occipital artery; $\mathrm{PCA}=$ posterior cerebral artery; $\mathrm{PICA}=$ posterior inferior cerebellar artery; SCA = superior cerebellar artery.

perioperative flow measurement techniques (quantitative MR angiography) and simple quantitative intraoperative flow measurement techniques (ultrasonic flow probe) have become readily available. ${ }^{15,16}$ These technological advances have streamlined the use of real-time flow analysis.

\section{Flow Measurement in Bypass Surgery}

\section{Flow-Based Approach}

A multidisciplinary approach that fully integrates quantitative flow analysis into the treatment of cerebral ischemia and aneurysms requiring bypass is the foundation of a flow-based approach to EC-IC bypass. A detailed understanding of flow can improve clinical outcomes by: 1) optimizing diagnosis, patient selection, and surgical planning; 2) improving technical success intraoperatively by providing a quantitative and empiric basis for decision making, assuring immediate patency and adequate flow; and 3) improving our ability to perform postoperative surveillance of graft patency and hemodynamic improvement. This report will review the use of flow measurement in cerebral revascularization and present algorithms for FAS planning, technique, and surveillance.

\section{Flow Measurement Technology}

In addition to standard operating equipment there are several items that are a standard part of FAS paradigms. These are the ultrasonic flow probe (Charbel microflow probe, Transonic Systems, Inc.) and quantitative MR angiography using NOVA software (VasSol, Inc.)

Quantitative MR Angiography. Volumetric flow rate in cerebral vessels can be measured noninvasively using a phase-contrast MR technique. The technique of blood flow quantification by quantitative MR angiography has been described previously, ${ }^{59}$ and is now implemented and enhanced with commercially available software called NOVA (VasSol, Inc.). Axial 2D or 3D time-of-flight MR angiography is performed and the acquired images are transmitted to a computer workstation where the NOVA software is used to create a rotating 3D surface rendering of the vasculature, including the circle of Willis, using a marching cube algorithm (Fig. 1a). From a scan line calculated by a line-fitting algorithm, a double-oblique scan is performed using gated $2 \mathrm{D}$ phase-contrast $\mathrm{MR}$, imaged perpendicular to the vessel axis. A flow report on each vessel of interest is created using the NOVA software; this report includes the mean volumetric flow rate (Fig. 1b). Images can be acquired using either a 1.5- or 3-T MR imaging unit (General Electric Medical Systems). Flow measurements performed on 1.5- and 3-T units have been demonstrated to be equivalent. ${ }^{60}$

Ultrasonic Flow Probe. Direct intraoperative flow measurements can be made with the use of a microvascular ultrasonic flow probe (Charbel Micro-flowprobe, Transonic Systems, Inc.). The device consists of an electronic flow detection unit and a flow-sensing perivascular probe. The flow probe uses the principle of ultrasonic transit time to sense flow in vessels independent of the flow velocity profile, turbulence, or hematocrit. ${ }^{15,16,37}$ The flow in milliliter/ minute appears as a waveform and as a digital display on the detection unit and is indicated as positive or negative depending on the direction of flow relative to the orientation of the probe. The probe is manufactured in a variety of sizes ranging from 1.5 to $3 \mathrm{~mm}$ in diameter. Close vessel contact with the probe is not required because the space 

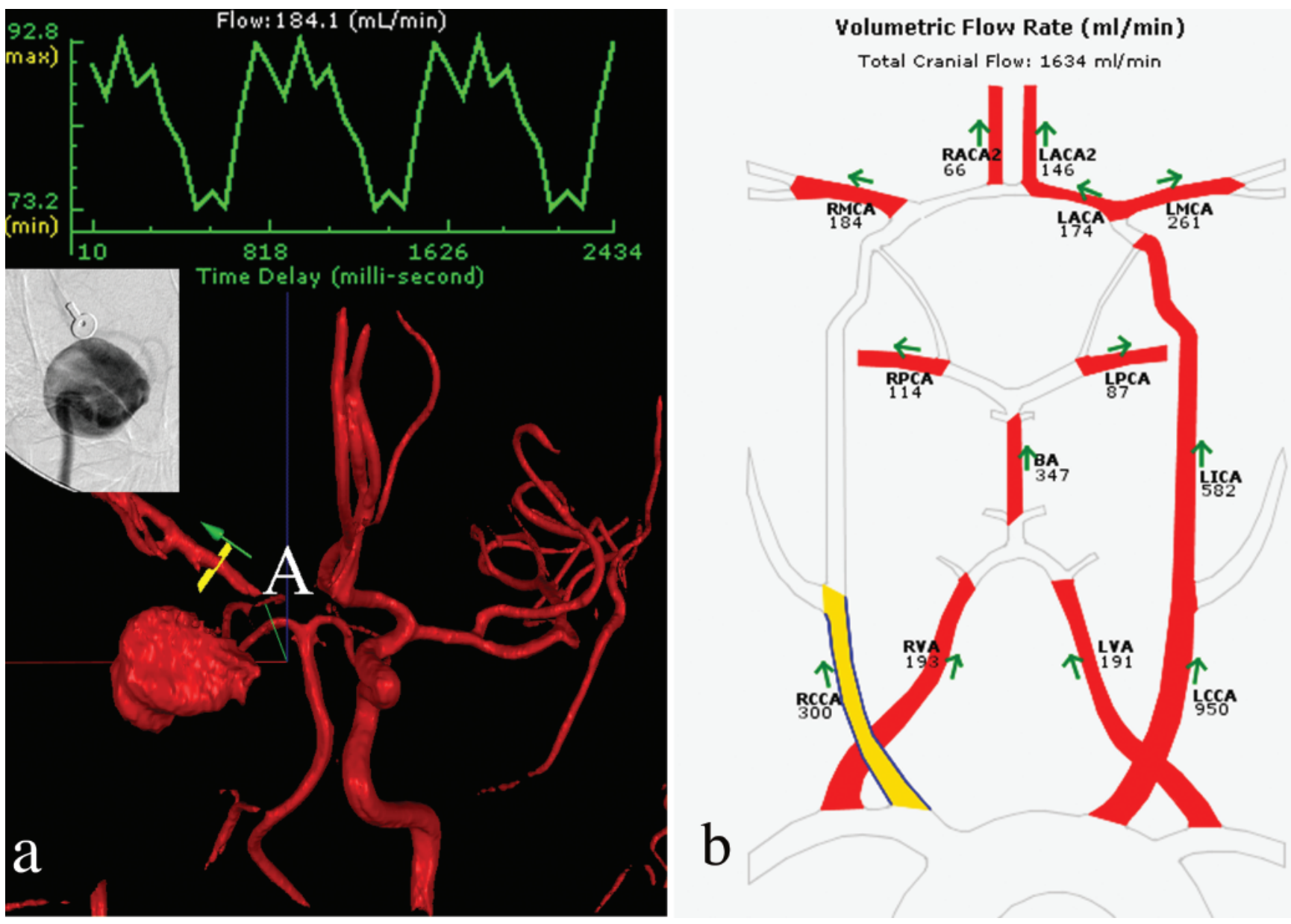

FIG. 1. Representative angiographic images, waveform, and flow rate map obtained in a 47-year-old man with a giant right cavernous aneurysm. a: Anterior and posterior circulation 3D NOVA quantitative MR angiogram, and the waveform in the right MCA. Inset: Anteroposterior projection of the right ICA. b: Representative mean volumetric flow rate map for the flow in the proximal and distal vessels. $\mathrm{A}=$ anterior; $\mathrm{BA}=$ basilar artery; $\mathrm{LACA}=$ left anterior cerebral artery, $\mathrm{A}_{1}$ segment; LACA2 = left anterior cerebral artery, $\mathrm{A}_{2}$ segment; LCCA = left common carotid artery; LICA = left ICA; LMCA = left MCA; LPCA = left posterior cerebral artery; LPCOM = left posterior communicating artery; LVA = left vertebral artery; RACA = right anterior cerebral artery, $\mathrm{A}_{1}$ segment; RACA2 = right anterior cerebral artery, $\mathrm{A}_{2}$ segment; $\mathrm{RCCA}=$ right common carotid artery; RICA = right ICA; RMCA = right MCA; RPCA = right posterior cerebral artery; $\mathrm{RPCOM}=$ right posterior communicating artery; RVA = right vertebral artery.

between the vessel and the encircling probe can be filled with an ultrasonic couplant such as saline. The accuracy of measurements with the ultrasonic flow probe has been well established with in vitro and in vivo studies. ${ }^{37}$

\section{Types of Bypass}

Cerebral revascularization is a powerful and versatile technique with broad indications. In general, however, the indications for this technique can be classified into 2 broad categories $^{4}$ : flow replacement ${ }^{4,32,39,46}$ and flow augmentation. $4,42,48$

\section{Bypass for Flow Replacement}

Bypass for flow replacement includes the treatment of complex aneurysms, skull base tumors, or other lesions that require blood flow to be rerouted to functioning brain areas to prevent symptomatic ischemia. Definitive management of giant or complex aneurysms may require sacrifice of the parent vessel. Permanent occlusion of the ICA is used successfully to treat inoperable intracranial aneurysms. ${ }^{22,41}$ Similarly, complete excision of skull base tumors occasionally requires resection of a major vessel. Although carotid sacrifice may be tolerated, ischemia and subsequent stroke 


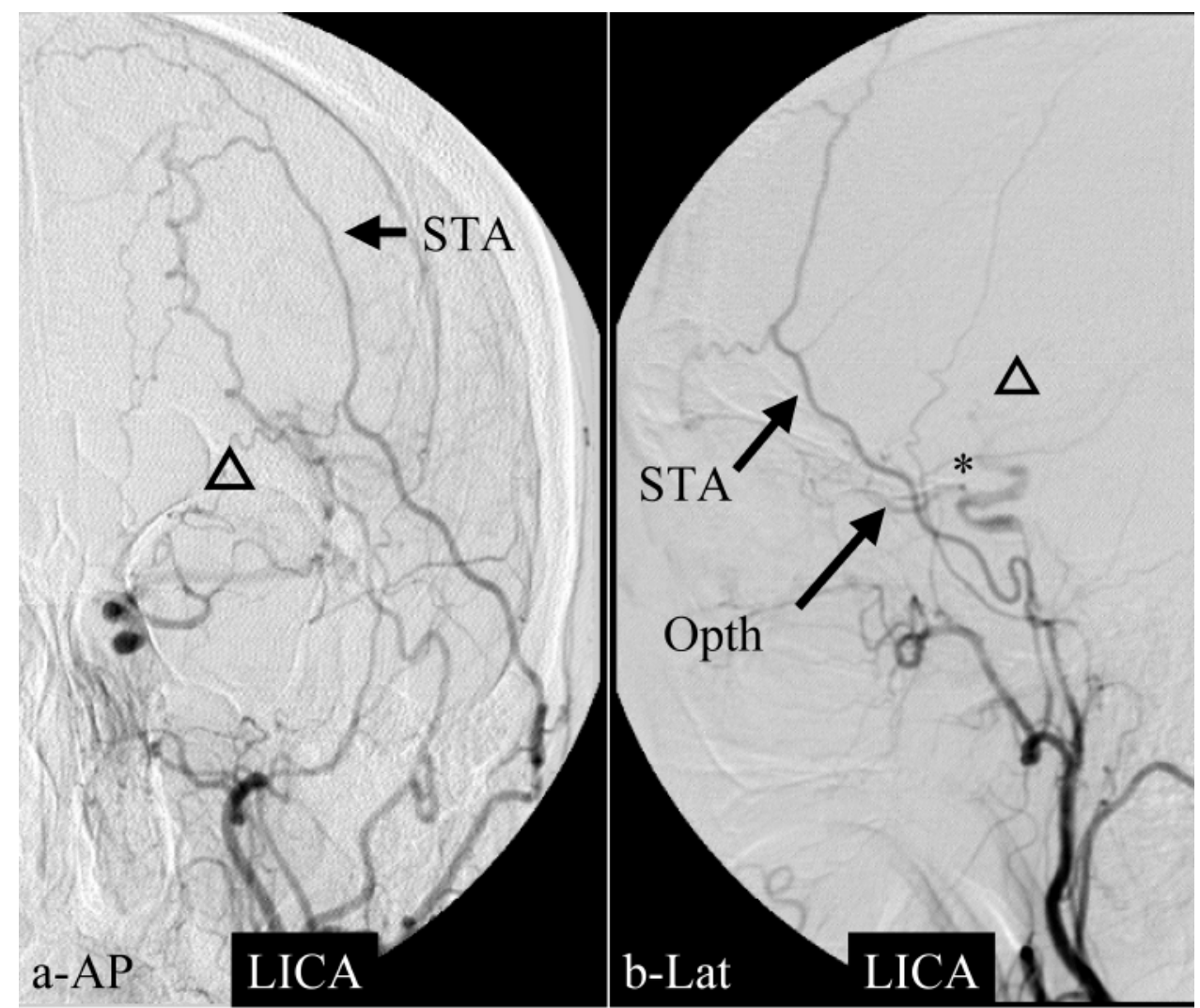

FIG. 2. Case 1. Digital subtraction cerebral angiograms (anteroposterior [a] and lateral [b]) of the left ICA showing occlusion and minimal perfusion of the left MCA territory (triangles) Some collateral flow (asterisk) to the left MCA territory from the ECA via the left ophthalmic (Opth) artery is noted.

can occur in up to $30 \%$ of patients. ${ }^{41}$ Studies evaluating cerebral perfusion during carotid ligation show that patients with signs of ischemia demonstrate $\mathrm{a} \geq 25 \%$ or greater decrease in blood flow during carotid ligation, whereas patients without ischemia have a $<25 \%$ decrease in blood flow. ${ }^{33}$ Applying this criterion before permanent carotid ligation shows that the incidence of ischemia can be reduced to $7 \%$ with a rejection rate of $39 \% .^{36}$ Some patients, therefore, are unable to provide adequate collateral flow ipsilateral to the site of ICA occlusion and are candidates for EC-IC bypass to avoid ischemic complications from carotid sacrifice. Fusiform or complex aneurysms of distal vessels, such as the MCA or its branches, typically also require revascularization using bypass techniques, because the collateral vessels to such terminal vessels are inadequate to avert stroke in the acute setting. Revascularization may be performed on a selective or universal basis.

\section{Extracranial-Intracranial Bypass for Flow Augmentation}

Anterior Circulation Ischemia. The use of EC-IC bypass to treat anterior circulation cerebral ischemia in the setting of atherosclerotic disease markedly declined after the unfavorable results of the randomized multicenter EC-IC Bypass Trial reported in $1985.23,24$ The trial failed to demonstrate benefit from surgical revascularization in patients with carotid artery occlusive disease. Subsequent studies have demonstrated that careful evaluation of patients with occlusive cerebrovascular disease can identify a subgroup with severe compromise in cerebrovascular reserve capacity, who are at higher risk for stroke $\mathrm{e}^{27,35,55}$ and who may be reasonable candidates for revascularization. In addition to the lack of hemodynamic selection criteria, the EC-IC Bypass Trial was criticized for selection bias.

Posterior Circulation Ischemia. The use of bypass for revascularization in patients with posterior fossa ischemia has been less studied than anterior circulation disease because of the relative prevalence of the conditions, the availability and evolution of endovascular techniques for treatment of vertebrobasilar stenosis, the relatively higher complication rate, and the technical complexity of posterior circulation revascularization. Existing studies indicate, however, the feasibility of various EC-IC bypass options to the posterior circulation, including occipital artery-posterior inferior cerebellar artery, ${ }^{11,34}$ superior cerebellar artery-posterior cerebral artery, ${ }^{49}$ STA-posterior cerebral artery, ${ }^{9}$ and STA-superior cerebellar artery ${ }^{10}$ bypasses. Symptomatic vertebrobasilar disease, particularly if intracranial vessels are affected, carries a high risk of stroke, averaging $10-15 \%$ per year despite medical therapy.,45 Therefore, patients who present with vertebrobasilar insufficiency refractory to maximal medical therapy and intracranial occlusive vertebrobasilar disease not amenable to endovascular angioplasty and stenting are potential candidates for posterior circulation EC-IC bypass. 

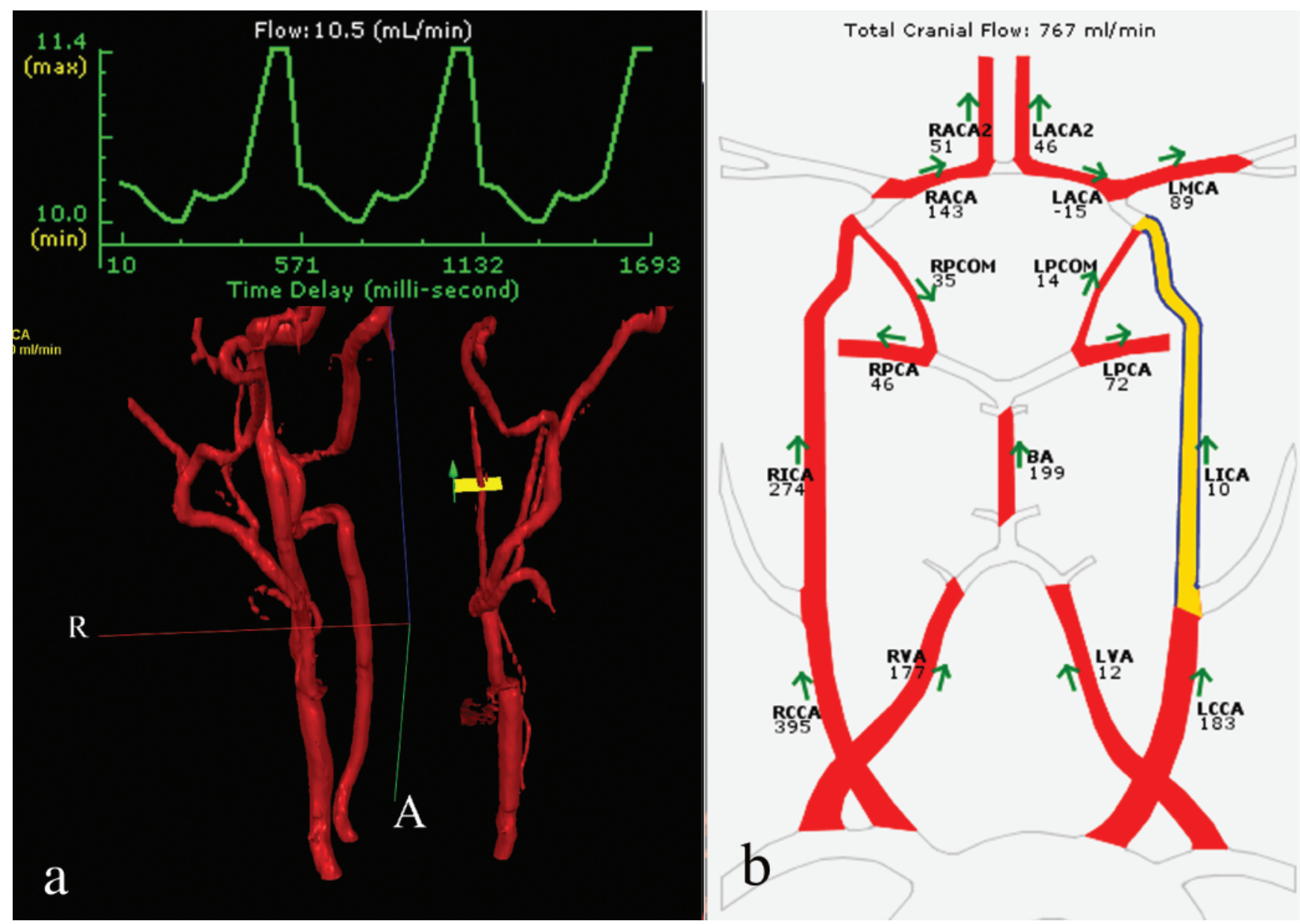

FIG. 3. Case 1. Three-dimensional NOVA quantitative MR angiography image and waveform (a), and flow map (b) showing a reduction in blood flow in the left hemisphere at baseline.

Moyamoya Disease. Moyamoya disease is marked by progressive diffuse stenosis of supraclinoid carotid vessels, the development of friable neovascular collateral networks, and the propensity to develop ischemic and hemorrhagic complications. ${ }^{25,52}$ Adult moyamoya is classically associated with hemorrhagic symptoms, while juvenile moyamoya has been associated with primarily ischemic presentations. ${ }^{25}$ However, this is based primarily on data taken from Japanese populations. Hallemeier et al..$^{29}$ recently described the baseline clinical features and outcomes in adults with moyamoya disease who were treated at a single North American institution. In this study, $24(71 \%)$ of 34 adult patients presented with ischemic symptoms. Medical therapy for symptomatic moyamoya disease is largely ineffective. Consequently, surgical revascularization has become the primary modality of treatment for patients who have this disease as a means of reducing the incidence of ischemic stroke and transient ischemic attack. Many authors have reported the efficacy of revascularization in this syndrome ${ }^{48}$ using either indirect revascularization with onlay grafts, direct EC-IC bypass with STA-MCA anastomosis, or a combination of both strategies. ${ }^{26,48}$ Indirect bypass demonstrates its best results in children, ${ }^{30}$ whereas direct STA-MCA bypass seems to offer greater benefit in adults. ${ }^{48}$

\section{Flow-Assisted Surgical Algorithms}

Over the past 5 years, over 100 revascularization procedures using flow-assisted strategies have been performed in our department. We have refined FAS revascularization through our experience, and now have very standardized methodologies. Although we have had great success with these algorithms, more work must be done to validate them on a larger, multiinstitutional scale. The FAS algorithms are presented below.

\section{Extracranial-Intracranial Bypass for Flow Augmentation in Ischemia}

Flow-Assisted Surgical Planning. Indications for performance of EC-IC bypass for ischemia have continued to evolve. For those patients with carotid occlusion, enrollment in the Carotid Occlusion Surgery Study is a priority. ${ }^{1,28}$ Otherwise, patients can be chosen for surgical revascularization on the basis of ongoing symptoms of cerebral ischemia in the setting of impaired hemodynamics. If angiography (Fig. 2) demonstrates significant occlusive disease with hypoperfusion, we consider a patient to be a candidate for revascularization if the following criteria are met: 1) the presence of symptomatic occlusive disease affecting 
W. W. Ashley Jr. et al.

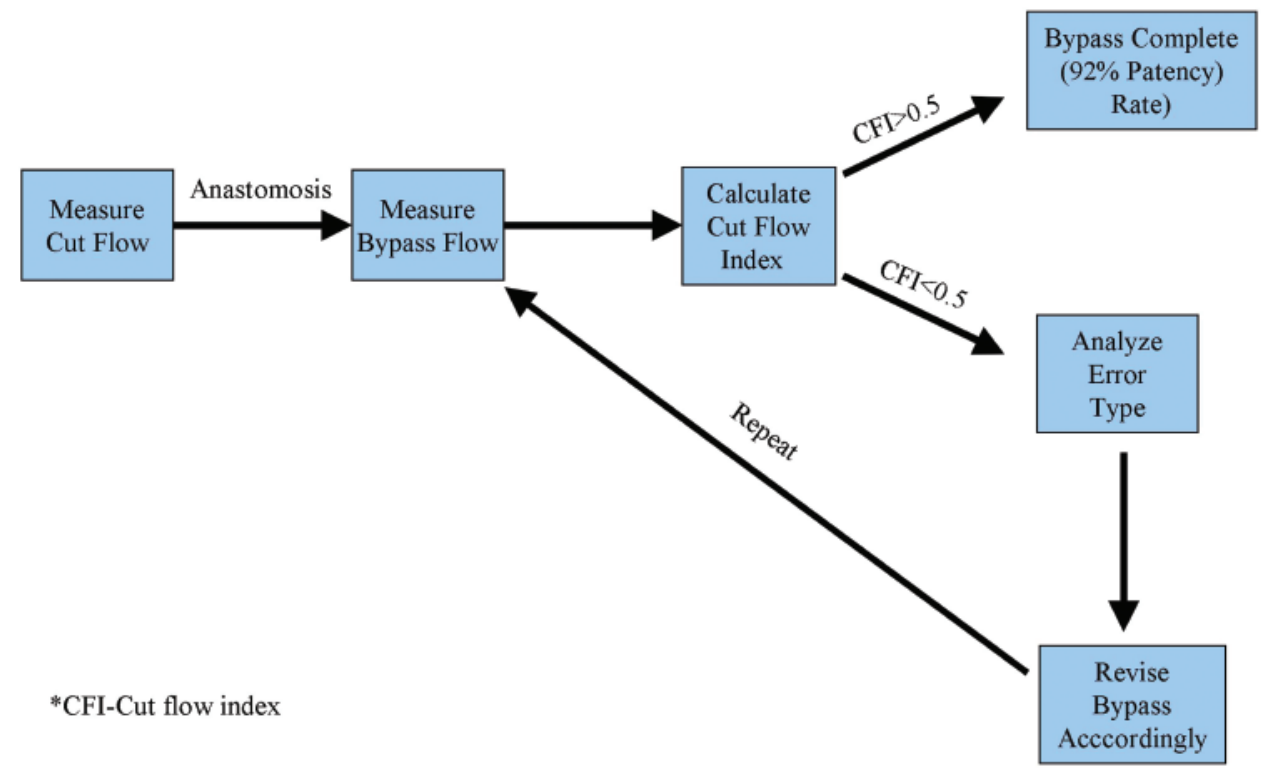

FIG. 4. Flow chart of FAS algorithm for flow augmentation

the anterior or posterior circulation with stroke or transient ischemic attacks despite medical therapy; 2) lack of medical comorbidities that contraindicate surgery; and 3) in anterior circulation disease, evidence of impaired cerebrovascular hemodynamics measured with functional MR imaging and MR perfusion studies with NOVA quantitative MR angiography (Fig. 3), augmented with hemodynamic reserve testing using acetazolamide. For posterior circulation disease, only quantitative MR angiography is used.

Quantitative MR angiography data collected in healthy volunteers of different age ranges has been gathered to provide normative data for blood flow in major intracranial vessels. When selecting patients for bypass, NOVA quantitative MR angiography intracranial flows can be compared to this normative data to gauge the degree of impairment. Moreover, the use of a vasodilatory challenge with acetazolamide allows assessment of the level of functional cerebrovascular reserve.

Flow-Assisted Surgical Technique. The STA-MCA bypass for flow augmentation is performed in the standard fashion. ${ }^{17,40}$ Application of the FAS technique (Fig. 4) to this procedure entails making flow measurements at 2 points intraoperatively. ${ }^{5}$ The first of these is the "cut flow" measurement. The cut flow is the maximal flow carrying capacity of the donor vessel (the STA). The flow in the intact STA is generally very low in situ, $<5-10 \mathrm{ml} /$ minute due to the small caliber of the vessel and the high resistance of the surrounding scalp tissue. However, once the vessel is freed from its tissue bed and the distal end is cut open, allowing blood to flow freely, the full carrying capacity of the vessel in the absence of downstream resistance can be measured - this is the cut flow of the vessel. The second flow measurement of importance is the "bypass flow." After the anastomosis, the flow in the STA is remeasured, which constitutes the flow in the bypass. If the resistance in the cortical recipient bed is sufficiently low, as would be expected in patients with hemodynamic compromise due to cerebrovascular occlusive disease, the bypass flow would be expected to be similar to the cut flow. This measure can be quantified as a CFI: CFI = bypass flow/cut flow.

This simple index provides insight into the success of the bypass operation, with a CFI of 1.0 indicating a highly successful bypass. It is important to keep blood pressure, endtidal $\mathrm{CO}_{2}$, and anesthetic technique (such as burst suppression) stable during measurements to avoid spuriously higher or lower flow results. The STA is also wrapped in a papaverine-soaked cottonoid after the initial dissection to relieve spasm related to vessel manipulation before measuring the cut flow.

The cut flow is used as an indicator of bypass function and predictor of bypass success. In a series of 51 bypass operations performed for flow augmentation in 47 patients, we found CFI to be a significant predictor of bypass patency $(\mathrm{p}<0.01) .{ }^{6}$ Using a CFI of 0.5 as a threshold value, the bypass patency rate was $92 \%$ in cases with CFIs $>0.5$, compared with $50 \%$ in cases with CFIs $<0.5$. Critical

TABLE 2

Summary of Type 1 and 2 error

\begin{tabular}{ccc}
\hline \hline Error Type & Summary & \multicolumn{1}{c}{ Description } \\
\hline Type 1 & $\begin{array}{c}\text { poor indication for } \\
\text { revascularization }\end{array}$ & $\begin{array}{c}\text { retrospective; recognition of this type } \\
\text { of error does not assist in altering the } \\
\text { operative plan, information gained in } \\
\text { this manner can help to modify the } \\
\text { future indications for performing the } \\
\text { procedure }\end{array}$ \\
Type 2 & $\begin{array}{l}\text { technical problem w/ } \\
\text { the graft relating } \\
\text { to the donor (2A), } \\
\text { the anastomosis } \\
\text { (2B), or the } \\
\text { recipient vessel/ } \\
\text { bed (2C) }\end{array}$ & $\begin{array}{l}\text { recognition of these errors may direct } \\
\text { intraoperative actions, such as reop- } \\
\text { ening \& revising an anastomosis for a } \\
\text { 2B error or considering a 2nd bypass } \\
\text { to a separate recipient using the } \\
\text { anterior STA branch for a 2C error }\end{array}$ \\
\hline
\end{tabular}



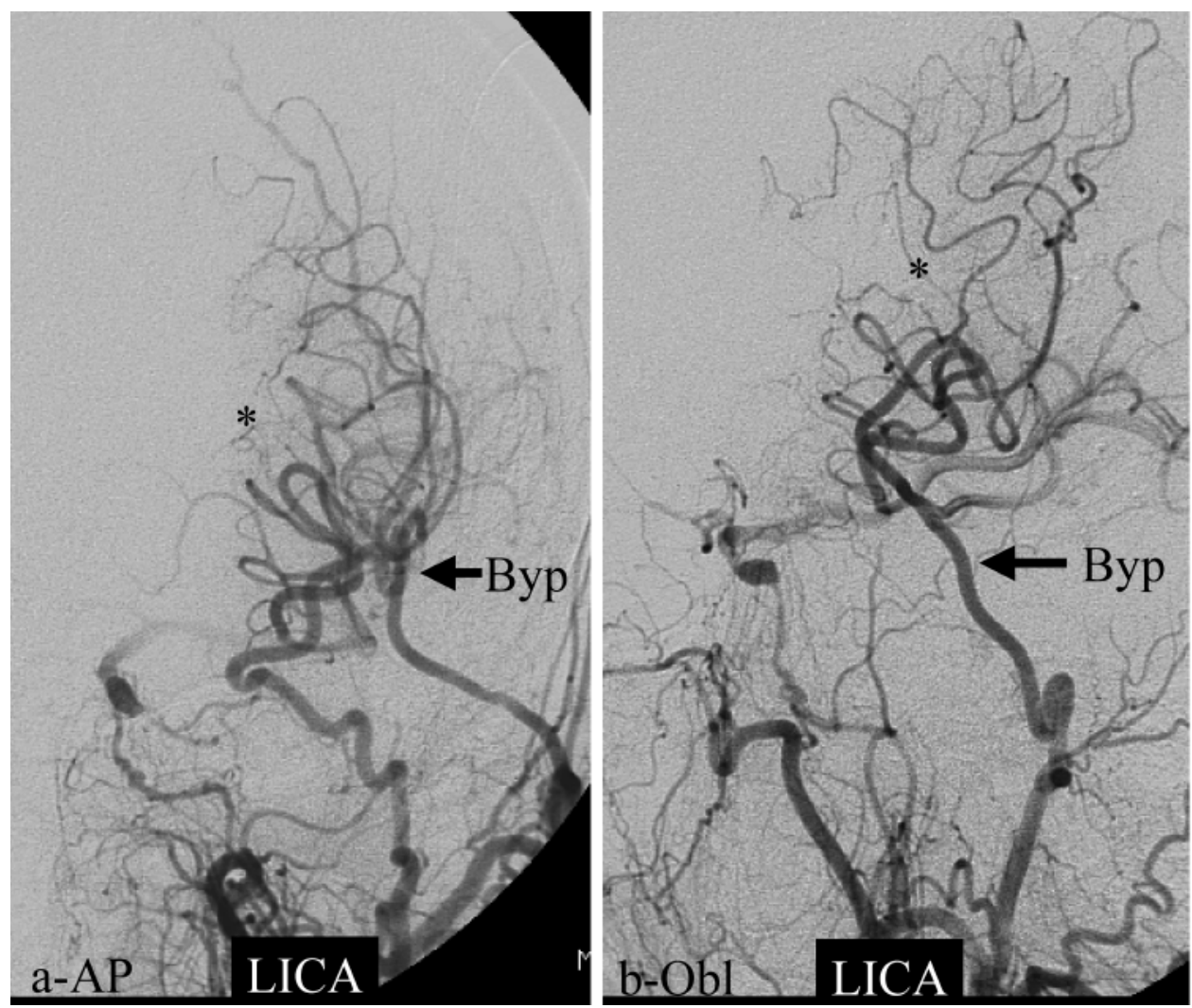

Fig. 5. Case 1. Postoperative angiograms (anteroposterior [a] and oblique [b]) of the left ICA demonstrating good graft filling immediately after surgery (arrow) and improved perfusion in the MCA territory (asterisk). Byp = bypass.

examination of the cases with poor CFIs reveals that a logical interpretation of bypass function can be performed intraoperatively. A low CFI can be a result of varying forms of intrinsic or extrinsic errors, which can be classified into Type 1 and Type 2 errors (Table 2). ${ }^{5}$

In summary, flow measurements allow immediate verification of bypass patency, and the CFI additionally provides a sensitive predictor of postoperative bypass patency. Given that bypasses with low CFIs are often patent at the time of surgery, our results highlight the notion that mere anatomical patency may not be as useful in predicting a successful bypass procedure as the assessment of intraoperative bypass flow (Fig. 5).

Flow-Assisted Surgical Surveillance. Assessment of EC-IC bypass patency and function has traditionally been performed using angiography. ${ }^{23,57}$ Less invasive modalities for early assessment and long-term follow-up after bypass are desirable. Noninvasive methods including Doppler ultrasonography and simple digital palpation have been used, ${ }^{51}$ but are less accurate and reliable than standard angiography. The imaging modalities of CT angiography and standard MR angiography are currently available for use in follow-up but do not provide dynamic flow information. Quantitative MR angiography provides the ability to noninvasively assess both the patency and the function of EC-IC bypasses by measuring flow through the bypass conduit. ${ }^{6.59}$

It is important to monitor the immediate and long-term functioning of bypasses. Quantitative MR angiography using NOVA allows bypass grafts to be assessed for patency and function in the postoperative period and over longterm serial monitoring. ${ }^{6}$ Stenosis or reduction in graft caliber is typically indicated by a low or rapidly decreasing flow. Just as direct intraoperative flow measurements provide valuable information, postoperative flow measurements similarly provide a useful functional assessment of bypass grafts. We perform qualitative MR angiography with NOVA in the immediate postoperative period and at serial follow-up intervals every 6-12 months. Formal angiography is reserved for patients who show diminished flow on NOVA quantitative MR angiography or patients who experience new neurologic symptoms. Quantitative MR angiography with NOVA can also quantify improvement in overall flow in the recipient vascular bed and improvement in hemodynamic reserve on acetazolamide testing.

\section{Illustrative Case 1: EC-IC Bypass for Flow Augmentation}

This 68-year-old man presented with a history of strokes. Cerebral angiography (Fig. 2) revealed left carotid artery occlusion with minimal perfusion of the left MCA territory. He was noted to have some collateral flow to the left MCA territory from the ECA via the left ophthalmic artery. He subsequently underwent full neurovascular evaluation, including NOVA quantitative MR angiography flow studies (Fig. 3), MR imaging and SPECT. A SPECT flow study 


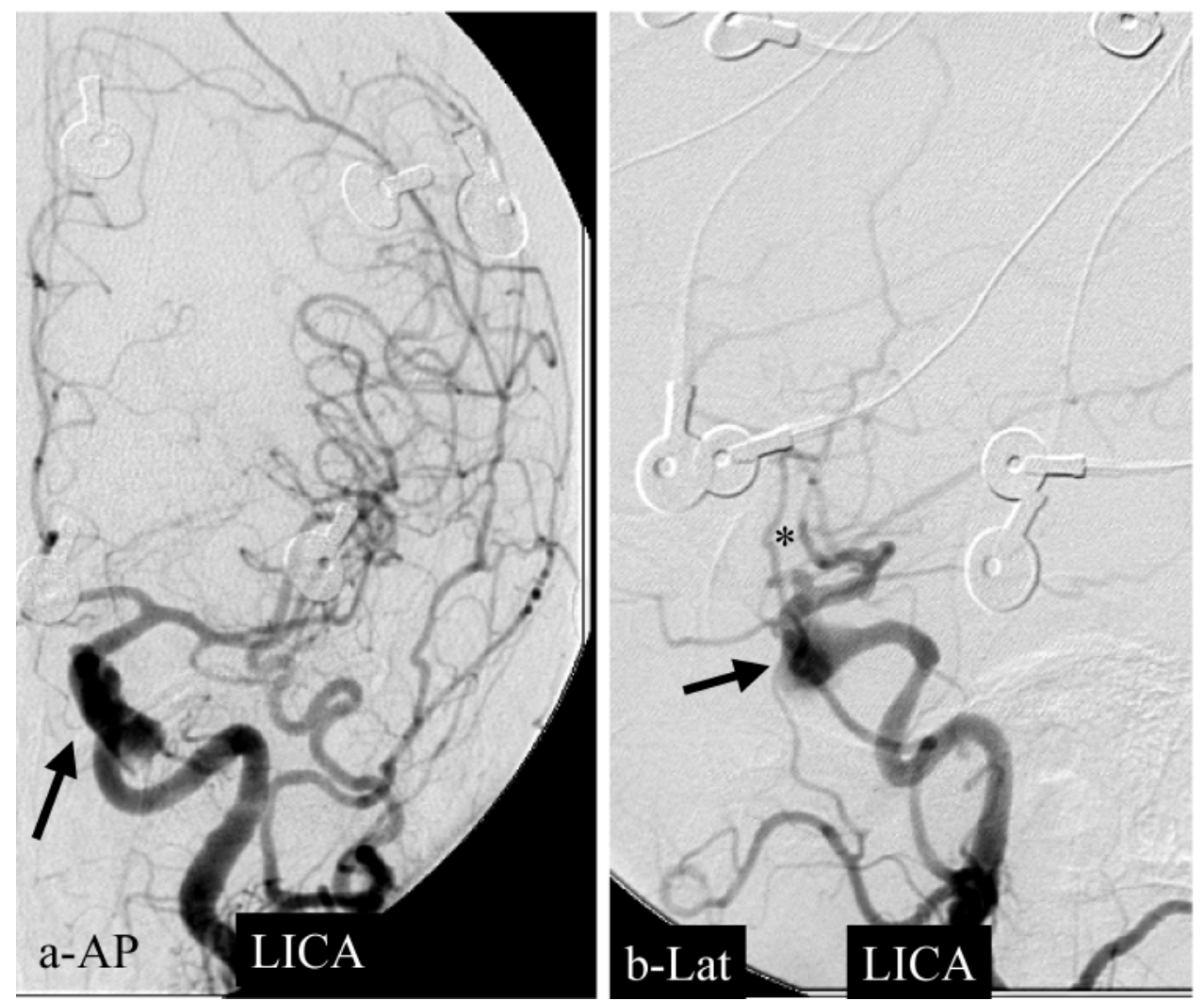

FIG. 6. Case 2. Digital subtraction cerebral angiograms (anteroposterior [a] and lateral [b]) showing a large, partially thrombosed (based on CT, not shown) left cavernous aneurysm (arrows) and small unruptured left paraclinoid aneurysm (asterisk) that is best seen in the lateral view (b).

demonstrated baseline reduction of blood flow in the left hemisphere. This reduction in flow was made even worse on acetazolamide challenge. The patient was believed to have symptomatic left carotid artery occlusion with a lack of cerebrovascular reserve. The NOVA quantitative MR angiography study (Fig. 3) shows that left ICA flow is minimal ( $10 \mathrm{ml} /$ minute), and flow in the left MCA distribution is also severely compromised ( $89 \mathrm{ml} /$ minute). Thus, after medical clearance, he was deemed a candidate for bypass. He underwent a bypass using the anterior branch of the STA. A FAS technique was used, and the measurements were as follows: STA cut flow rate was $57 \mathrm{ml} /$ minute, the initial bypass flow was $26 \mathrm{ml} /$ minute when measured under burst suppression, and the final bypass flow was 42 $\mathrm{ml} /$ minute measured under active electroencephalography conditions. His initial CFI (26/57) of 0.46 was somewhat worrisome. After removal of burst suppression, the CFI (42/57) of 0.74 was more reassuring. The initial CFI represents a Type 1 error because the hemodynamic need was underestimated due to the fact that the patient was under burst suppression. This emphasizes the importance of taking FAS measurements under stable physiological conditions. Postoperative angiograms were obtained (Fig. 5), and demonstrated that the graft was filling well and the MCA territory perfusion had improved. Because the CFI was $>$ 0.5 , this graft will probably be durable.

\section{Extracranial-Intracranial Bypass for Flow Replacement in} Planned Vessel Sacrifice

Flow-Assisted Surgical Planning. The initial diagnosis of a giant aneurysm or other lesions requiring bypass for planned vessel sacrifice is achieved using standard 4-vessel digital subtraction angiography (Fig. 6). The focus is placed on the anatomy of the lesion, as well as the collateral vessels, and size and location of potential donor vessels.

To determine tolerance to carotid artery sacrifice, patients undergo the endovascular BOT, during which their response to temporary carotid artery occlusion is evaluated based on neurological, radiographic, electrophysiological, perfusion, and provocative testing criteria. Although some surgeons advocate a universal approach to revascularization, we prefer a selective approach based on the results of BOT. We recently published a review of BOT and our selection criteria. ${ }^{4}$ If BOT fails, the patient requires revascularization prior to carotid artery sacrifice. The results of BOT in addition to intraoperative assessment can also help determine the strategy for revascularization. Failure of the BOT based on clinical criteria suggests that a high-flow bypass is necessary. If failure of the BOT is based on provocative testing, a low-flow bypass may be adequate. Traditionally, the use of high- and low-flow bypass strategies have been based on estimates of flow and carrying 


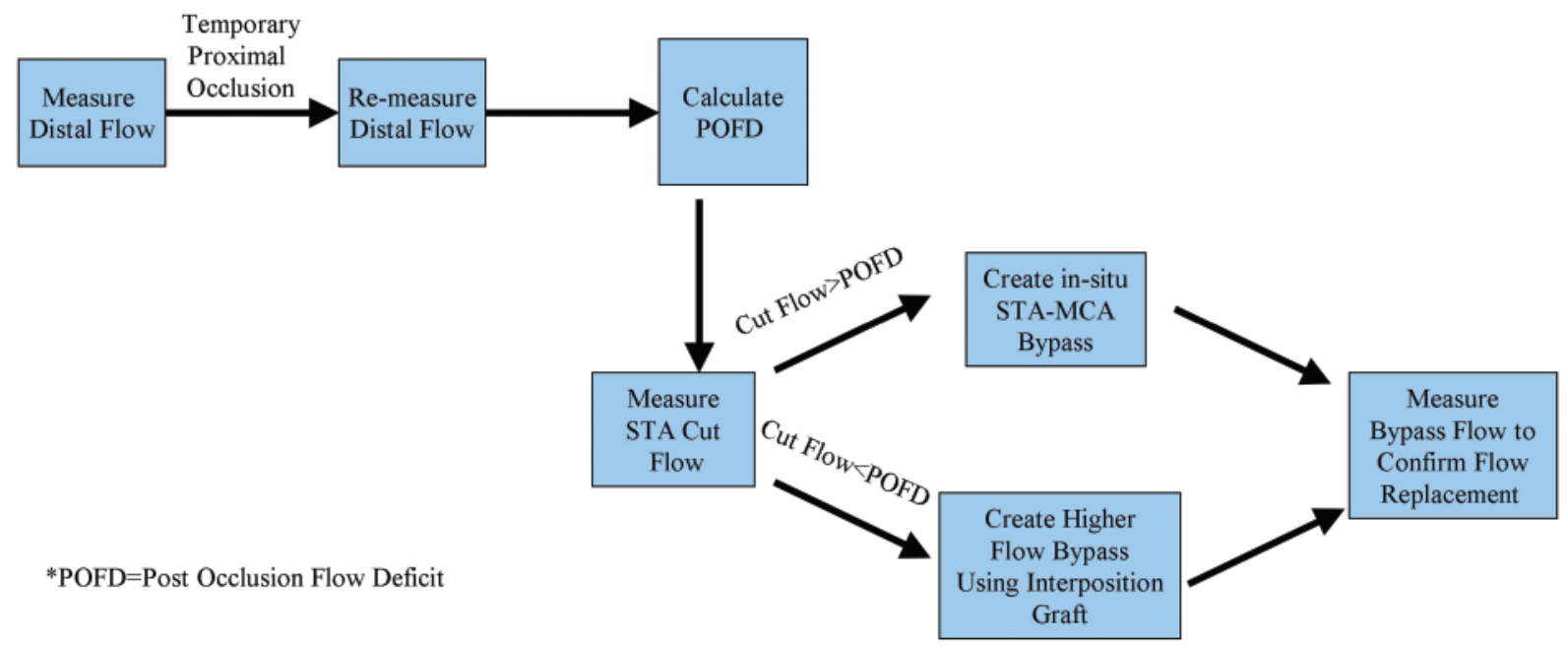

FIG. 7. Flow chart of FAS algorithm for flow replacement. POFD = postocclusion flow deficit

capacity in potential donor vessels and conduits, respectively. Intraoperative flow measurements can augment this traditional strategy by providing empiric quantitative information.

The next step in FAS planning is the use of NOVA quantitative MR angiography, which allows direct measurement of the flow in the vessel(s) proximal and distal to the lesion. This information can provide some insight into the amount of flow that will need to be replaced once the vessel is sacrificed, and provide a baseline measurement for postoperative comparison.

Flow-Assisted Surgical Technique. Flow-assisted surgical technique for flow replacement requires 4 intraoperative measurements (Fig. 7). In carotid artery aneurysms (such as in cavernous, ophthalmic, or paraclinoid locations), the flow in the distal ICA or the MCA trunk can be measured intraoperatively with the flow probe both before and after temporary carotid artery occlusion to measure the flow deficit directly. The bypass can then be tailored according to the flow replacement needed. The STA may provide adequate flow replacement depending on its carrying capacity, which can be assessed by measuring its cut flow. In preparation for the necessary flow measurements, the cervical carotid artery is exposed for proximal temporary occlusion, and the STA is routinely preserved. If the cut flow of the STA is adequate, an STA-MCA bypass is created. If the STA cannot provide adequate carrying capacity to replace the flow deficit, an interposition graft using saphenous vein or radial artery anastomosed to the STA trunk or the cervical carotid artery can be used. At the completion of the bypass, whether using the STA as an in situ pedicle graft or an interposition graft, the flow in the bypass is measured to confirm adequate flow replacement (Fig. 8).

For fusiform or complex terminal aneurysms located on more distal vessels beyond the collateral of the circle of Willis, such as the ICA terminus, the MCA and posterior inferior cerebellar artery are used to determine the distal flow in the vessels at risk of compromise once the aneurysm is subjected to trapping or proximal occlusion. Once the distal territory flow has been measured, the adequacy of in situ pedicle grafts such as the STA for anterior circula- tion aneurysms, or the ophthalmic artery for posterior circulation lesions, such as posterior inferior cerebellar artery aneurysms, can be assessed by their cut flow. If inadequate to provide the necessary flow replacement to the territory at risk, then an interposition graft is required. At the completion of the bypass and after parent vessel occlusion, the bypass flow is measured to ensure that it matches the original territory flow determined at baseline. In a bypass for flow replacement in the setting of planned vessel sacrifice, the FAS technique provides a mechanism for guiding graft selection to provide the optimal revascularization strategy. Furthermore, the function and adequacy of the bypass graft can be verified intraoperatively.

Occasionally during aneurysm surgery, it becomes apparent that an aneurysm is "unclippable" and that unplanned vessel sacrifice will be necessary. We have also developed a novel strategy for intraoperative COT as part of our FAS technique. As part of a selective revascularization strategy, the intraoperative COT determines a patient's tolerance for carotid artery occlusion. The COT can provide real-time quantitative information for direct assessment of the adequacy of collateral flow postocclusion at baseline and under hemodynamic challenge. To perform the COT, distal flow is measured as described above; the carotid artery is then temporarily occluded with a clip, and distal flow is measured again. If the distal flow is maintained and there are no significant changes, a vasodilatory challenge is performed to assess adequacy of the cerebrovascular reserve. This is accomplished by inducing hypercapnia (a 10-tmm $\mathrm{Hg}$ increase in end-tidal $\mathrm{CO}_{2}$ ) and determining whether the distal flow changes appropriately in response.

Flow-Assisted Surgical Surveillance. Monitoring of bypass function can be routinely followed using quantitative MR angiography. ${ }^{9}$ Assessment in the postoperative period prior to discharge, and at 6-12-month intervals dependent upon the patient's clinical status, can be performed simply and noninvasively. Postoperative angiograms can be limited to cases that show a change or decrement in bypass flow over time. Although standard angiography enables visual confirmation of patency and filling in the 

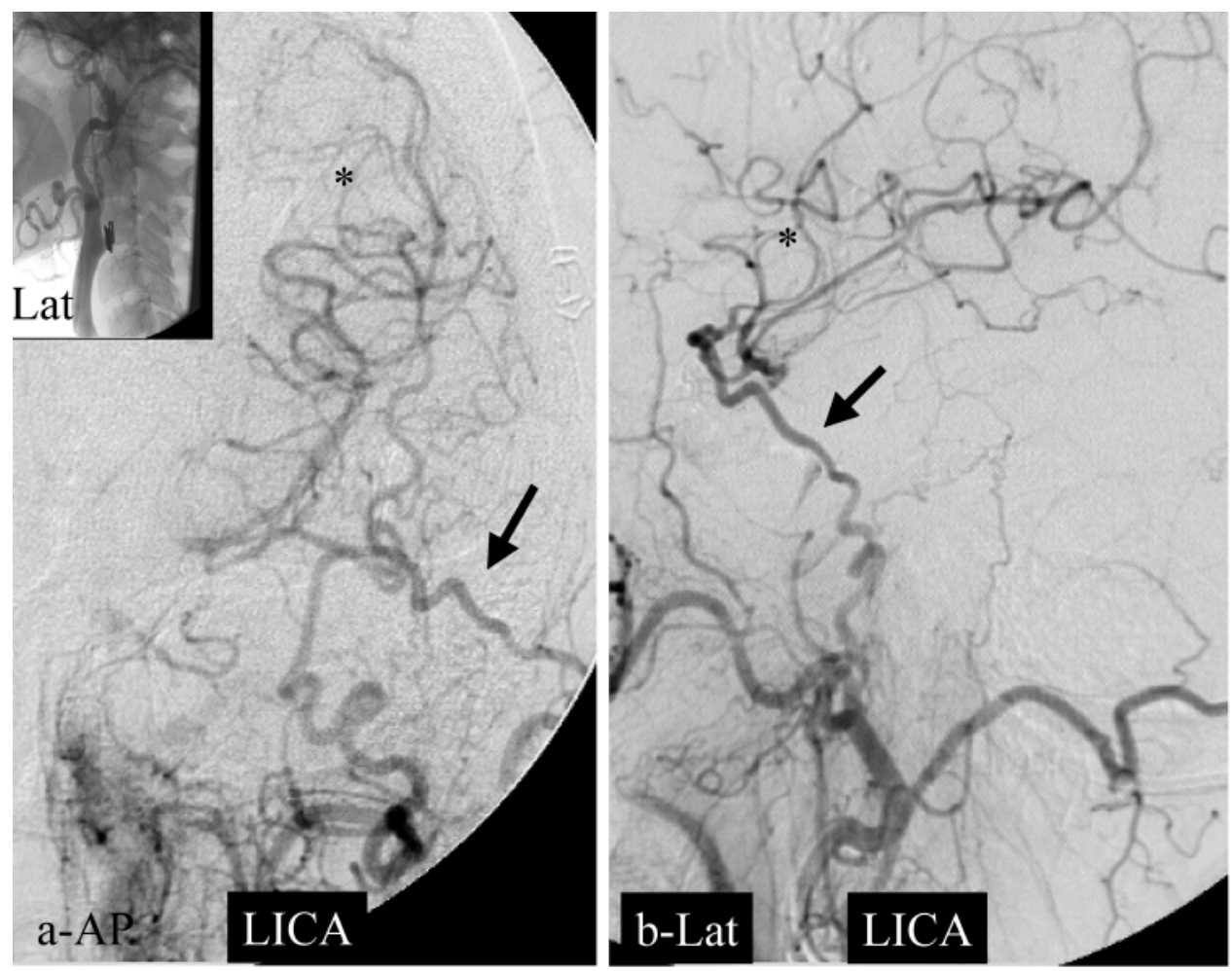

FIG. 8. Case 2. Postoperative angiograms (anteroposterior [a] and lateral [b]) of the left ICA showing graft patency (arrows) and good perfusion of the MCA territory (asterisk). The cavernous aneurysm was occluded proximally by occluding the ICA neck with clips (inset). After treatment the cavernous aneurysm can no longer be seen.

recipient vascular bed, NOVA quantitative MR angiography provides quantitative data for serial follow-up. Our experience with the use of quantitative MR angiography in evaluating EC-IC bypass postoperatively ${ }^{6}$ indicates that it is a reliable and efficient noninvasive modality in serial follow-up of bypass function and postbypass hemodynamic alterations. Additionally, the flow in the revascularized vessels can be measured directly and compared to baseline to confirm the adequacy of the bypass strategy.

\section{Illustrative Case 2: EC-IC Bypass for Flow Replacement}

This 61-year-old woman presented with ophthalmoplegia. Angiography studies revealed a large, partially thrombosed, left cavernous aneurysm, and a small, unruptured left paraclinoid aneurysm (Fig. 6). Balloon occlusion testing was performed, and failed based on SPECT criteria. She was therefore unlikely to tolerate carotid artery occlusion and would need a bypass for flow replacement. The FAS technique was used, and the initial distal MCA flow was $55 \mathrm{ml} /$ minute. After temporary ICA occlusion, the distal MCA flow was $40 \mathrm{ml} /$ minute, representing a 30\% decrease in flow after occlusion and confirming the need for bypass. Fortunately, the STA cut flow rate was $30 \mathrm{ml} /$ minute which was adequate to provide enough additional flow to account for the flow deficit ( 55 minus $40 \mathrm{ml} / \mathrm{min}$ ute) of $15 \mathrm{ml} /$ minute. After an STA-MCA bypass was performed, the bypass flow more than matched the deficit at $28 \mathrm{ml} /$ minute. After the bypass was completed, the paraclinoid aneurysm was clipped, and the cavernous aneurysm was occluded proximally by clipping the ICA (Fig. 8 inset).
On postoperative angiography, the graft was shown to be patent and perfusing the MCA territory; the cavernous aneurysm was not seen.

\section{Conclusions}

Recently there has been renewed interest in cerebral revascularization. The disappointing results of the EC-IC Bypass Study focused practitioners' attention on refining the indications for bypass and improving patient selection techniques. Flow measurements can be used to improve identification of patients who would benefit from revascularization, improve our technical ability to perform bypass, and improve our ability to monitor the patients. The upcoming results of the Carotid Occlusion Surgery Study ${ }^{28}$ and the Japanese EC-IC Bypass Trial ${ }^{38,43}$ have the potential to greatly enhance the ability to select patients for bypass. Bypass technology has improved and in the coming years nonocclusive $^{54}$ and automated ${ }^{18}$ bypass techniques may become standard. Likewise, flow measurement technology and its applications continue to evolve through clinical and applied research. Finally, although the current focus is primarily on first order analysis of flow data, both NOVA quantitative MR angiography and the transonic flow probe provide waveform data that allow analysis of higher order functions such as acceleration and turbulence that may have an effect on overall bypass success. As the amount of useful empiric flow data increases and as the understanding of the hemodynamic factors improves, the ability to perform bypass safely and effectively will continue to ad- 
vance. Flow-assisted surgical planning, technique, and surveillance methodologies have proven extremely useful at our institution, but it must be emphasized that further validation of their utility is needed to firmly establish their use.

\section{Disclosure}

Fady T. Charbel, M.D., is a consultant for Transonics Systems, Inc., and has a financial interest in VasSol, Inc., the developer of NOVA.

\section{References}

1. Adams HP Jr, Powers WJ, Grubb RL Jr, Clarke WR, Woolson RF: Preview of a new trial of extracranial-to-intracranial arterial anastomosis: the carotid occlusion surgery study. Neurosurg Clin N Am 12:613-624, 2001

2. Amaducci L, Flamm ES, Haynes RB, Mohr JP, Peerless SJ, Robertson JT, et al: The international EC/IC bypass study. Stroke 13: 247-248, 1982

3. Amin-Hanjani S, Butler WE, Ogilvy CS, Carter BS, Barker FG II: Extracranial-intracranial bypass in the treatment of occlusive cerebrovascular disease and intracranial aneurysms in the United States between 1992 and 2001: a population-based study. J Neurosurg 103:794-804, 2005

4. Amin-Hanjani S, Charbel FT: Is extracranial-intracranial bypass surgery effective in certain patients? Neurol Clin 24:729-743, 2006

5. Amin-Hanjani S, Du X, Mlinarevich N, Meglio G, Zhao M, Charbel FT: The cut flow index: an intraoperative predictor of the success of extracranial-intracranial bypass for occlusive cerebrovascular disease. Neurosurgery 56:75-85, 2005

6. Amin-Hanjani S, Shin JH, Zhao M, Du X, Charbel FT: Evaluation of extracranial-intracranial bypass using quantitative magnetic resonance angiography. J Neurosurg 106:291-298, 2007

7. Anonymous: Prognosis of patients with symptomatic vertebral or basilar artery stenosis. The Warfarin-Aspirin Symptomatic Intracranial Disease (WASID) Study Group. Stroke 29: 1389-1392, 1998

8. Ausman JI, Diaz FG: Critique of the extracranial-intracranial bypass study. Surg Neurol 26:218-221, 1986

9. Ausman JI, Diaz FG, Vacca DF, Sadasivan B: Superficial temporal and occipital artery bypass pedicles to superior, anterior inferior, and posterior inferior cerebellar arteries for vertebrobasilar insufficiency. J Neurosurg 72:554-558, 1990

10. Ausman JI, Lee MC, Chater N, Latchaw RE: Superficial temporal artery to superior cerebellar artery anastomosis for distal basilar artery stenosis. Surg Neurol 12:277-282, 1979

11. Ausman JI, Nicoloff DM, Chou SN: Posterior fossa revascularization: anastomosis of vertebral artery to PICA with interposed radial artery graft. Surg Neurol 9:281-286, 1978

12. Awad IA, Spetzler RF: Extracranial-intracranial bypass surgery: a critical analysis in light of the International Cooperative Study. Neurosurgery 19:655-664, 1986

13. Barnett HJ, Sackett D, Taylor DW, Haynes B, Peerless SJ, Meissner I, et al: Are the results of the extracranial-intracranial bypass trial generalizable? N Engl J Med 316:820-824, 1987

14. Carrel A: The Surgery of Blood Vessels. Bull Johns Hopkins Hosp 18:18-28, 1907

15. Charbel FT, Hoffman WE, Misra M, Hannigan K, Ausman JI: Role of a perivascular ultrasonic micro-flow probe in aneurysm surgery. Neurol Med Chir (Tokyo) 38 Suppl:35-38, 1998

16. Charbel FT, Hoffman WE, Misra M, Ostergren L: Ultrasonic perivascular flow probe: technique and application in neurosurgery. Neurol Res 20:439-442, 1998

17. Charbel FT, Meglio G, Amin-Hanjani S: Superficial temporal artery-to-middle cerebral artery bypass. Neurosurgery 56 (1 Suppl):186-190, 2005

18. Dacey RG, Zipfel G, Ashley W, Chicoine M, Reinert M: Auto- mated, compliant, high-flow common carotid to middle cerebral artery bypass, in 69th Annual Meeting of the American Academy of Neurological Surgery. Henderson, Nevada, 2007. Rolling Meadows, Ill: AANS, 2007, pp 66-67

19. Derdeyn CP, Powers WJ, Grubb RL Jr: Hemodynamic effects of middle cerebral artery stenosis and occlusion. AJNR Am J Neuroradiol 19:1463-1469, 1998

20. Derdeyn CP, Yundt KD, Videen TO, Carpenter DA, Grubb RL Jr, Powers WJ: Increased oxygen extraction fraction is associated with prior ischemic events in patients with carotid occlusion. Stroke 29:754-758, 1998

21. Donaghy RPM, Yaşargil M: Extra-intracranial blood flow diversion, in Annual Meeting of the American Association of Neurological Surgeons. Chicago, Illinois, 1968. Rolling Meadows, Ill: AANS, 1968, Abstract \#52

22. Drake CG, Peerless SJ, Ferguson GG: Hunterian proximal arterial occlusion for giant aneurysms of the carotid circulation. J Neurosurg 81:656-665, 1994

23. The EC/IC Bypass Study Group: Failure of extracranial-intracranial arterial bypass to reduce the risk of ischemic stroke. Results of an international randomized trial. N Engl J Med 313:11911200,1985

24. The EC/IC Bypass Study Group: The International Cooperative Study of Extracranial/Intracranial Arterial Anastomosis (EC/IC Bypass Study): methodology and entry characteristics. Stroke 16:397-406, 1985

25. Fukui M: Guidelines for the diagnosis and treatment of spontaneous occlusion of the circle of Willis ('moyamoya' disease). Research Committee on Spontaneous Occlusion of the Circle of Willis (Moyamoya Disease) of the Ministry of Health and Welfare, Japan. Clin Neurol Neurosurg 99 (2 Suppl): S238-S240, 1997

26. Golby AJ, Marks MP, Thompson RC, Steinberg GK: Direct and combined revascularization in pediatric moyamoya disease. Neurosurgery 45:50-60, 1999

27. Grubb RL Jr, Derdeyn CP, Fritsch SM, Carpenter DA, Yundt KD, Videen TO, et al: Importance of hemodynamic factors in the prognosis of symptomatic carotid occlusion. JAMA 280:1055-1060, 1998

28. Grubb RL Jr, Powers WJ, Derdeyn CP, Adams HP Jr, Clarke WR: The Carotid Occlusion Surgery Study. Neurosurg Focus 14(3):E9, 2003

29. Hallemeier CL, Rich KM, Grubb RL Jr, Chicoine MR, Moran CJ, Cross DT III, et al: Clinical features and outcome in North American adults with moyamoya phenomenon. Stroke 37:1490 1496, 2006

30. Houkin K, Kuroda S, Nakayama N: Cerebral revascularization for moyamoya disease in children. Neurosurg Clin N Am 12:575584,2001

31. Jacobson JH, Suarez EL: Microsurgery in anastomosis of small vessels. Surg Forum 11:243-245, 1960

32. Javedan SP, Deshmukh VR, Spetzler RF, Zabramski JM: The role of cerebral revascularization in patients with intracranial aneurysms. Neurosurg Clin N Am 12:541-555, 2001

33. Jennett WB, Harper AM, Gillespie FC: Measurement of regional cerebral blood-flow during carotid ligation. Lancet 2:1162-1163, 1966

34. Khodadad G: Occipital artery-posterior inferior cerebellar artery anastomosis. Surg Neurol 5:225-227, 1976

35. Kleiser B, Widder B: Course of carotid artery occlusions with impaired cerebrovascular reactivity. Stroke 23:171-174, 1992

36. Leech PJ, Miller JD, Fitch W, Barker J: Cerebral blood flow, internal carotid artery pressure, and the EEG as a guide to the safety of carotid ligation. J Neurol Neurosurg Psychiatry 37:854-862, 1974

37. Lundell A, Bergqvist D, Mattsson E, Nilsson B: Volume blood flow measurements with a transit time flowmeter: an in vivo and in vitro variability and validation study. Clin Physiol 13:547-557, 1993 
38. Mizumura S, Nakagawara J, Takahashi M, Kumita S, Cho K, Nakajo H, et al: Three-dimensional display in staging hemodynamic brain ischemia for JET study: objective evaluation using SEE analysis and 3D-SSP display. Ann Nucl Med 18:13-21, 2004

39. Newell DW, Skirboll SL: Revascularization and bypass procedures for cerebral aneurysms. Neurosurg Clin N Am 9:697-711, 1998

40. Newell DW, Vilela MD: Superficial temporal artery to middle cerebral artery bypass. Neurosurgery 54:1441-1449, 2004

41. Nishioka $\mathrm{H}$ : Results of the treatment of intracranial aneurysms by occlusion of the carotid artery in the neck. J Neurosurg 25: 660-704, 1966

42. Nussbaum ES, Erickson DL: Extracranial-intracranial bypass for ischemic cerebrovascular disease refractory to maximal medical therapy. Neurosurgery 46:37-43, 2000

43. Ogasawara K, Ogawa A: [JET study (Japanese EC-IC Bypass Trial).] Nippon Rinsho 64 (7 Suppl):524-527, 2006 (Jpn)

44. Pool JL, Potts D (eds): Aneurysms and Arteriovenous Anomalies of the Brain. Diagnosis and Treatment. New York: Harper \& Row, Inc, 1965, pp 221-222

45. Qureshi AI, Ziai WC, Yahia AM, Mohammad Y, Sen S, Agarwal $\mathrm{P}$, et al: Stroke-free survival and its determinants in patients with symptomatic vertebrobasilar stenosis: a multicenter study. Neurosurgery 52:1033-1040, 2003

46. Sekhar LN, Duff JM, Kalavakonda C, Olding M: Cerebral revascularization using radial artery grafts for the treatment of complex intracranial aneurysms: techniques and outcomes for 17 patients. Neurosurgery 49:646-659, 2001

47. Spetzler R, Chater N: Occipital artery-middle cerebral artery anastomosis for cerebral artery occlusive disease. Surg Neurol 2:235-238, 1974

48. Srinivasan J, Britz GW, Newell DW: Cerebral revascularization for moyamoya disease in adults. Neurosurg Clin N Am 12: 585-594, 2001

49. Sundt TM Jr, Campbell JK, Houser OW: Transpositions and anastomoses between the posterior cerebral and superior cerebellar arteries. Report of two cases. J Neurosurg 55:967-970, 1981

50. Sundt TM Jr, Piepgras DG, Houser OW, Campbell JK: Interposition saphenous vein grafts for advanced occlusive disease and large aneurysms in the posterior circulation. J Neurosurg 56:205-215, 1982
51. Sundt TM Jr, Whisnant JP, Fode NC, Piepgras DG, Houser OW: Results, complications, and follow-up of 415 bypass operations for occlusive disease of the carotid system. Mayo Clin Proc 60: 230-240, 1985

52. Suzuki J, Takaku A: Cerebrovascular "moyamoya" disease. Disease showing abnormal net-like vessels in base of brain. Arch Neurol 20:288-299, 1969

53. Tew JM Jr: Reconstructive intracranial vascular surgery for prevention of stroke. Clin Neurosurg 22:264-280, 1975

54. Tulleken CA, Verdaasdonk RM: First clinical experience with Excimer assisted high flow bypass surgery of the brain. Acta Neurochir Wien 134:66-70, 1995

55. Webster MW, Makaroun MS, Steed DL, Smith HA, Johnson DW, Yonas H: Compromised cerebral blood flow reactivity is a predictor of stroke in patients with symptomatic carotid artery occlusive disease. J Vasc Surg 21:338-345, 1995

56. Woringer E, Kunlin J: [Anastomosis between the common carotid and the intracranial carotid or the sylvian fissure artery by a graft, using the suspended suture technique.] Neurochirugie 200:181188, 1963 (Fr)

57. Yaşargil MG, Yonekawa Y: Results of microsurgical extra-intracranial arterial bypass in the treatment of cerebral ischemia. Neurosurgery 1:22-24, 1977

58. Yonas H, Jungreis C: Xenon CT cerebral blood flow: past, present, and future. AJNR Am J Neuroradiol 16:219-220, 1995

59. Zhao M, Charbel FT, Alperin N, Loth F, Clark ME: Improved phase-contrast flow quantification by three-dimensional vessel localization. Magn Reson Imaging 18:697-706, 2000

60. Zhao M, Curcio A, Clark ME, Zhou X, Charbel FT: In-vitro validation of MR volumetric flow measurements, in 2004 International Workshop on Flow and Motion, 2004, pp 148-149

Manuscript submitted January 10, 2008.

Accepted January 14, 2008.

This work was supported in part by funding from the Dr. Ralph and Marian Falk Foundation.

Address correspondence to: Sepideh Amin-Hanjani, M.D., Department of Neurosurgery, University of Illinois at Chicago, Neuropsychiatric Insitutute (MC 799), 912 South Wood Street, Chicago, Illinois 60612. email: hanjani@uic.edu. 